\title{
The Bicontact Hip Arthroplasty System
}

\author{
A Modular System for Cementless and Cemented Prosthesis \\ Development and Experiences After 20 Years
}

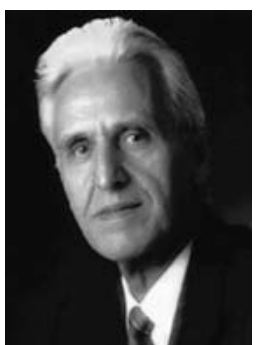

S. Weller

\section{Implant Development \\ $\nabla$}

"Constant, critical exchange of experience and opinion in the area of clinical and basic research is an essential requirement for progress!"

Numerous new constructive ideas and further developments in the area of hip arthroplasty have been communicated in recent decades, implemented and introduced into clinical practice. Looking back at the basic concepts, materials and types of prosthesis, they have led to fundamental and visible improvements.

Cement fixation of the prosthetic parts, initiated by Charnley in 1959/60, had a fundamental overall influence on joint replacement and promoted its clinical use with additional introduction of the "low friction principle" in joint replacement. A second era of joint replacement, so to speak, was instituted in recent decades with the "cementless biological implantation technique". Many very unpleasant experiences with sometimes difficult situations after cemented hip replacements with extensive bone defects and abnormal perfusion, favour cementless implantation, whenever possible, especially in younger patients who have a longer life expectancy.

Even if the basic problem of permanent prosthetic fixation - i.e., a long-term connection between a "living tissue and a dead material" - has not yet been solved in principle: it will continue to be necessary to choose between and decide on cemented and cementless implantation, as far as possible intraoperatively, depending on the individual situation, particularly the patient's age and life expectancy, the quality and bearing capacity of the bone.

\footnotetext{
Bibliografie

DOI 10.1055/s-2007-965651 Z Orthop Unfall 2007; 145 :

S1-S2 @ Georg Thieme

Verlag KG Stuttgart • New York . ISSN 1864-6697

Korrespondenzadresse

Prof. Dr. med. Dr. h. c. mult.

Siegfried Weller

Engelfriedshalde 47

72076 Tübingen

Phone: +49707162634

Fax: +49707167747

Siwetue@aol.com
}

\section{Biology and Bone Preservation $\nabla$}

In view of the worldwide increase in newly implanted joint replacements and growing problems with revision operations, in future all our efforts will have to concentrate on improving the initial situation with less primary bone loss and also the long-term results in case implant revision becomes necessary later on. The causes of implant loosening on the mechanical side are implantation technique, a change in loading and wear, and on the biological side, bone remodeling and atrophy, influenced by disorders of physiological bone metabolism - osteoporosis, bone necrosis, immunological, and allergic reactions.

Bone is a living tissue that reacts to changing loads with constant adaptation and is not a plinth made of dead unalterable material into which an implant can be inserted and fixed permanently.

The biological environment with the demand for long-term preservation of bone metabolism that is disturbed as little as possible is best met by cementless fixation with growth of bone onto the implant - "osseointegration".

Thus biological causes play a particularly important part long-term - "stability alone does not assure a good long-term result". As in other areas of implant surgery, "biology" in the broadest sense has been too little regarded in joint replacement. Every primary implantation must consider the possibility of later revision and, therefore, aim to "preserve as much bone as possible!" No bone should be sacrificed unnecessarily as this is greatly needed in the long term, especially in the event of revision. In elderly patients with already marked osteoporosis, reduced bone strength and shorter life expectancy, however, these techniques are usually less help- and useful. In these cases, bone cement can act as a stabiliser during fixation. Immediate loading is particularly important, while long-term stability tends to be of secondary importance.

The answer to the question "with or without cement?" will have to continue to be: "Both, cemented and uncemented, adapted to the individual situation". In general, the decision on whether to use cement should always consider the hip arthroplasty that is optimal for the individual patient.

\section{Bicontact System Experience $\nabla$}

With the development and introduction of the Bicontact hip arthroplasty system 20 years ago, the intention was not just to add another model to the numerous developments of the most varied prosthesis types of the early years. Since its introduction, the overall modular system of the Bicontact hip arthroplasty and its philosophy 
have taken into account the demands of a prosthetic system that are summarized below after many years of experiences and have borne them in mind, particularly from the clinical aspect.

Our demands for a hip replacement system 1985/86:

- Can be used universally (cemented/cementless - primary operation, revision, etc.).

- Simple and easily comprehensive instruments (for all surgical techniques).

- Substance- i.e., bone-preserving operation techniques (biological implantation technique).

- Optimal prosthesis design with high primary stability (especially rotational stability with cementless technique).

- Improvement of bearing materials with low wear (polyethylene, metal, ceramic, etc.).

- Improvement of long-term results (survival, prospective studies).

- Economically justifiable use (costs).

After 20 years of experience with these demands, the results of prospective control statistics with the Bicontact system - without altering the basic concept and implant design - confirm the intellectual approach from the earlier experiences and the considerations listed above.

This special supplement edition of the "Zeitschrift für Orthopädie und Unfallchirurgie" ("Journal of Orthopaedics and Trauma Surgery") on the occasion of the 20th anniversary of the introduction of the Bicontact hip arthroplasty system reports on various aspects and experiences of Bicontact users for many years and their collaboration. In the midst of the individual publications is our own recent study on "Prospective long-term follow-up of the cementless Bicontact hip stem with Plasmapore coating". Individual articles deal with the description of the basic concept, the biomechanical considerations and demands, the design, ma- terial and technical features in special indications, the operative technique together with after-care and follow-up. The problems of revision operations are addressed and the results of expanded solution possibilities with the Bicontact revision system are reported.

\section{Patient Counselling}

$\nabla$

Critical considerations and communications on the question of the physical loading of the arthroplasty patient emphasise the necessity and prognostic importance of detailed pre- and postoperative instruction and counselling of the patient.

"The patient must deal with his artificial joint intelligently" (Küsswetter) in other words: "He must learn to live with his joint replacement."

This demand is still far too little regarded as the indications for early joint replacement are being increasingly extended, especially in younger patients.

\section{Acknowledgements}

Particular thanks go to the authors of the individual articles and their colleagues, who with the reports of their experiences have helped to provide an up-to-date picture of our current knowledge of hip arthroplasty and especially of the use of the Bicontact hip arthroplasty system. The editors of the "Zeitschrift für Orthopädie und Unfallchirurgie" (Journal of Orthopaedics and Trauma Surgery), members of the editorial board and not at least the publishers have provided every assistance and support for this special edition. 